07,03

\title{
Две стадии формирования повреждения при ударном воздействии на поликристаллические соединения $\mathrm{ZnS}$ и $\mathrm{ZnSe}$
}

\author{
(C) И.П. Щербаков ${ }^{1}$, А.А. Дунаев ${ }^{2}$, А.Е. Чмель ${ }^{1, \text { ฯ }}$ \\ ${ }^{1}$ Физико-технический институт им. А.Ф. Иофрее РАН, \\ Санкт-Петербург, Россия \\ ${ }^{2}$ гОИ им. С.И. Вавилова, \\ Санкт-Петербург, Россия \\ ฯ E-mail: chmel@mail.ioffe.ru
}

(Поступила в Редакцию 19 октября 2017 г.)

Механолюминесценция (МЛ) в пластичных твердых телах объясняется движением заряженных дислокаций в деформируемом материале. В хрупких телах основным источником МЛ служат разрывы межатомных связей с последующей реконфигурацией электронной структуры. В работе исследована МЛ в керамиках из ионно-ковалентных соединений $\mathrm{ZnS}$ и $\mathrm{ZnSe}$, возникающая при ударной нагрузке, превышающей предел деформации. В зависимости от метода получения и термообработки керамики имели различный размер и геометрию зерен-кристаллитов и строение межзеренных границ, что, предположительно, может существенно повлиять на скольжение дислокаций. Показано, что в обоих материалах временнб́е развертки импульсов МЛ имеют два хорошо разрешенных пика. Положение пиков на временно́й оси существенно зависело от величины кристаллитов, образующих керамику, и в менышей степени от барьерных свойств межзеренных границ. Первый пик был связан с пластической деформацией, предшествующей разрушению кристаллической структуры. Второй пик возникал при зарождении трещин при разрыве межатомных связей и локальной деформации материала в вершинах растущих трещин. Распределения амплитуд импульсов МЛ (зависимости количества импульсов от их амплитуды), рассчитанные по отдельности для обоих пиков, следуют степенному закону, что указывает на коррелированный характер электронных процессов при различных механизмах их возбуждения (движение дислокаций - разрывы связей).

DOI: 10.21883/FTT.2018.04.45689.296

\section{1. Введение}

Эффект механолюминесценции наблюдается во всех классах диэлектриков, включая неорганические $[1,2]$ и органические [3] кристаллы, стекла [4] и другие гомогенные и гетерогенные твердые тела. Однако механизм индуцированного свечения различен в пластичных и хрупких материалах. В деформируемых пластичных телах, таких как щелочно-галоидные кристаллы, люминесценция возникает вследствие движения заряженных дислокаций, которые создают сильное электрическое поле, под действием которого электроны из ловушек переходят в зону проводимости; рекомбинации электрондырка сопровождаются излучением света $[5,6]$. Эффект генерации света после достижения предельной деформации, насколько нам известно, никогда не затрагивался. Между тем, известно, что при разрушении хрупких тел реконфигурация электронной структуры при разрыве межатомных связей также сопровождается люминесценцией [7].

В работе [8] исследован эффект МЛ в ударно-деформируемых поликристаллических ионно-ковалентных соединениях $\mathrm{ZnS}$ и $\mathrm{ZnSe}$. Сообщалось, что временны́е развертки МЛ, т.е. зависимости амплитуды МЛ $(A)$ от времени после удара $(t)$, имеют два хорошо выраженных максимума, тогда как в исследованиях эффекта МЛ в хрупких телах всегда наблюдался единственный пик [9]. Сопоставление с развертками сигналов акустической эмиссии (АЭ), генерируемых растущими микротрещинами, показало точное совпадение более позднего пика МЛ с одиночным пиком АЭ. Было высказано предположение [8], что первый всплеск свечения в $\mathrm{ZnSe}$ (в дальнейшем пик 1) был вызван пластической деформацией поликристалла, тогда как пик, совпадающий с максимумом АЭ (пик 2), возникал при индуцированном ударом растрескивании образца.

Особенностью поликристаллических материалов являются границы зерен, которые препятствуют свободному движению дислокаций при деформирующей нагрузке. Поэтому можно было ожидать значительной зависимости эффекта МЛ от микроструктуры, геометрической и кристаллографической ориентации пластичных керамик. В настоящей работе происхождение пиков МЛ в керамиках $\mathrm{ZnS}$ и $\mathrm{ZnSe}$ рассмотрено с точки зрения роли межзеренных границ и размеров зерен, исходя из положения максимумов пиков и распределений энергии (амплитуд) во временны́х сериях свечения $A$ vs $t$ в образцах с различной степенью неоднородности. Проблема разрушения материалов $\mathrm{ZnS}$ и $\mathrm{ZnSe}$ имеет практическое значение. Пластичные керамики $\mathrm{ZnS}$ и $\mathrm{ZnSe}$ широко применяются в ИК оптических устройствах переднего обзора на мобильных носителях, где они подвергаются 
ударам твердых пылевых частиц и атмосферных осадков, повреждающих поверхность изделий $[10,11]$. Кроме того, благодаря способности люминесцировать при пластической деформации [12] и механическом разрушении [8] эти материалы используются в качестве механолюминесцентных датчиков динамических воздействий в авиакосмической технике [13], автомобилестроении [14] и других областях.

\section{2. Образцы и оборудование}

Исследованы коммерческие и собственные образцы керамик, приготовленных методами горячего прессования (hot pressing, HP), физического парового осаждения (physical vapor deposition, PVD) и химического парового осаждения (chemical vapor deposition, CVD), размер зерен в которых различался на 2 порядка (табл. 1), а микротвердость $H_{V}-$ почти в полтора раза ( 1800 MPa для $\mathrm{ZnS}$ и $\sim 1350 \mathrm{MPa}$ для $\mathrm{ZnSe})$. Некоторые образцы подвергались дополнительной обработке методом горячего изостатического прессования (hot isostatic pressing, HIP), которая в результате рекристаллизации почти устраняет межкристаллитные границы, формируя тонкие равновесные слои между крупными зернами [15]. Ниже метод получения материала будет указываться верхним индексом, например, $\mathrm{ZnS}^{\mathrm{HP}}, \mathrm{ZnS}^{\mathrm{CVD}}, \mathrm{ZnSe}^{\mathrm{PVD}+\mathrm{HIP}}$ и т. д.

Образцы в форме дисков диаметром 20-30 mm и толщиной 1-2 mm помещали на массивную металлическую подставку с нанесенным слоем консистентной смазки. Повреждение производили ударом груза, падающего с высоты $10 \mathrm{~cm}$ на заостренный боек из закаленной стали, поставленный на поверхность образца. Люминесценция с поверхности образца собиралась кварцевой линзой и направлялась на вход фотоумножителя ФЭУ-136. Сигналы МЛ поступали на вход аналоговоцифрового преобразователя АСК-3106 и в цифровой форме сохранялись в компьютере. Временно́е разрешение записи сигналов $10 \mathrm{~ns}$, продолжительность сбора сигналов $400 \mu \mathrm{s}$.

Таблица 1. Средний размер зерен и приблизительные температуры синтеза керамик $\mathrm{A}_{2} \mathrm{~B}_{6}$, полученных различными методами

\begin{tabular}{c|c|c|c}
\hline $\begin{array}{c}\text { Метод } \\
\text { синтеза }\end{array}$ & Материал & $\begin{array}{c}\text { Температура } \\
\text { синтеза, }{ }^{\circ} \mathrm{C}\end{array}$ & $\begin{array}{c}\text { Средний размер } \\
\text { зерен, } \mu \mathrm{mm}\end{array}$ \\
\hline $\mathrm{HP}$ & $\mathrm{ZnS}$ & 950 & $1-2$ \\
& $\mathrm{ZnSe}$ & 1150 & $\sim 100$ \\
$\mathrm{PVD}$ & $\mathrm{ZnSe}$ & 1050 & $500-1000$ \\
$\mathrm{PVD}+\mathrm{HIP}$ & $\mathrm{ZnSe}$ & 1100 & $1000-1500^{*}$ \\
$\mathrm{CVD}$ & $\mathrm{ZnS}$ & 700 & $\sim 10$ \\
$\mathrm{CVD}+\mathrm{HIP}$ & $\mathrm{ZnS}$ & 950 & $200-250^{*}$
\end{tabular}

* Межкристаллитные границы слабо выражены.
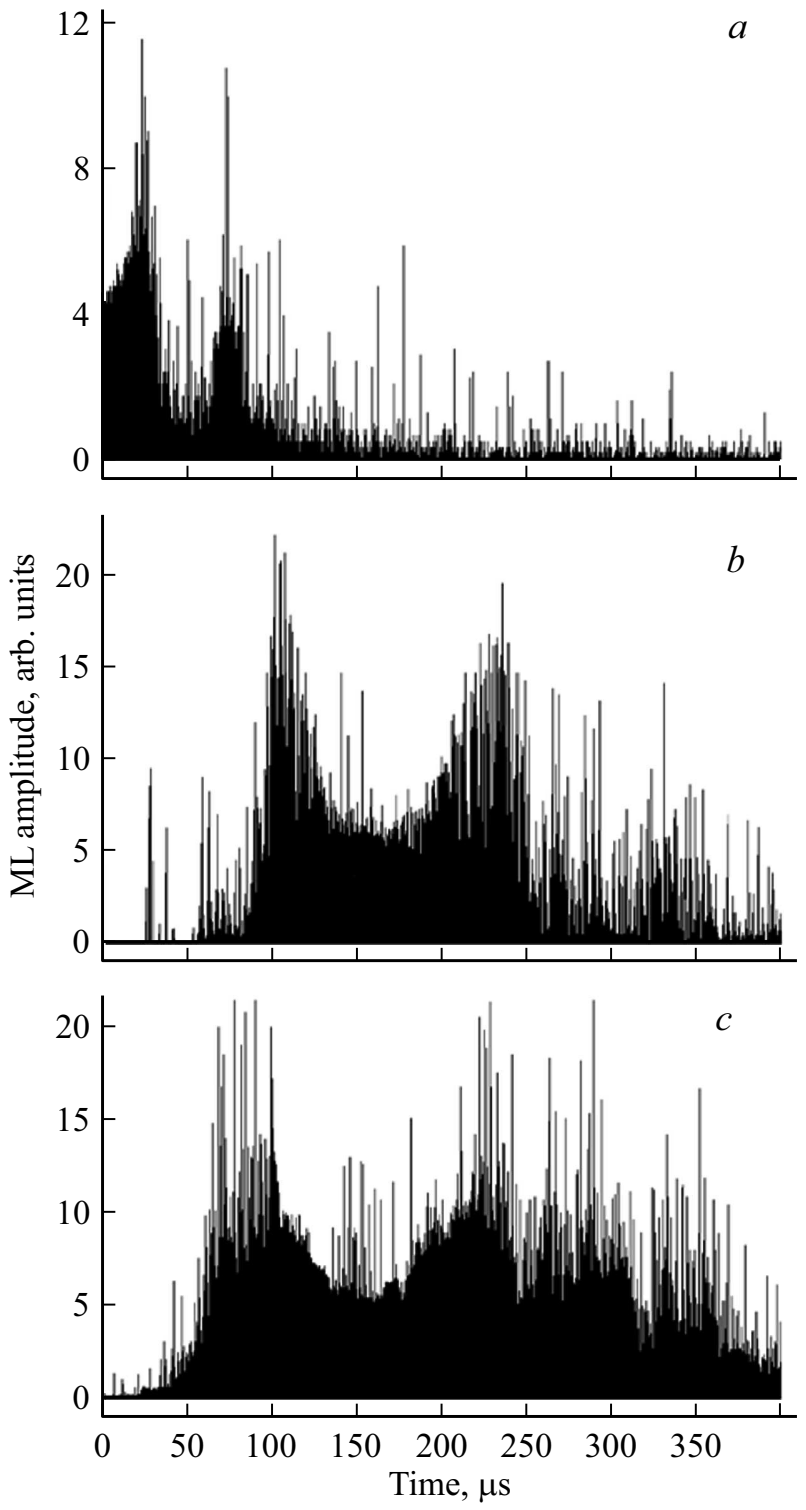

Рис. 1. Временнб́е серии импульсов МЛ при ударном воздействии на керамики $\mathrm{ZnS}^{\mathrm{HP}}(a), \mathrm{ZnS}^{\mathrm{CVD}}(b)$ и $\mathrm{ZnS} \mathrm{CVD}^{\mathrm{CHIP}}(c)$.

\section{3. Результаты}

3.1. Временны́ е развертки.На рис. 1 показаны временные развертки МЛ в керамиках $\mathrm{ZnS}$, полученных методами HP, CVD, CVD + HIP, на рис. 2 - развертки для керамик $\mathrm{ZnSe}$, приготовленных с помощью методов HP, PVD и PVD + HIP. Можно видеть, что для всех образцов отклик МЛ на механическое воздействие проявлялся двумя пиками с различными временами задержки от момента удара; в дальнейшем первый по времени максимум свечения обозначается как пик 1, а последующий - как пик 2. В обоих материалах наименьшая временна́я задержка пар пиков была в мелкозернистых керамиках $\mathrm{ZnS}^{\mathrm{HP}}$ и $\mathrm{ZnSe} \mathrm{HP}^{\mathrm{HP}}$. Пики МЛ в керамиках $\mathrm{ZnS} \mathrm{CVD}^{\mathrm{V}}$ и $\mathrm{ZnSe} \mathrm{PVD}^{\mathrm{PV}}$ имели бо́льшую задержку, причем после их обработки горячим изостатическим 


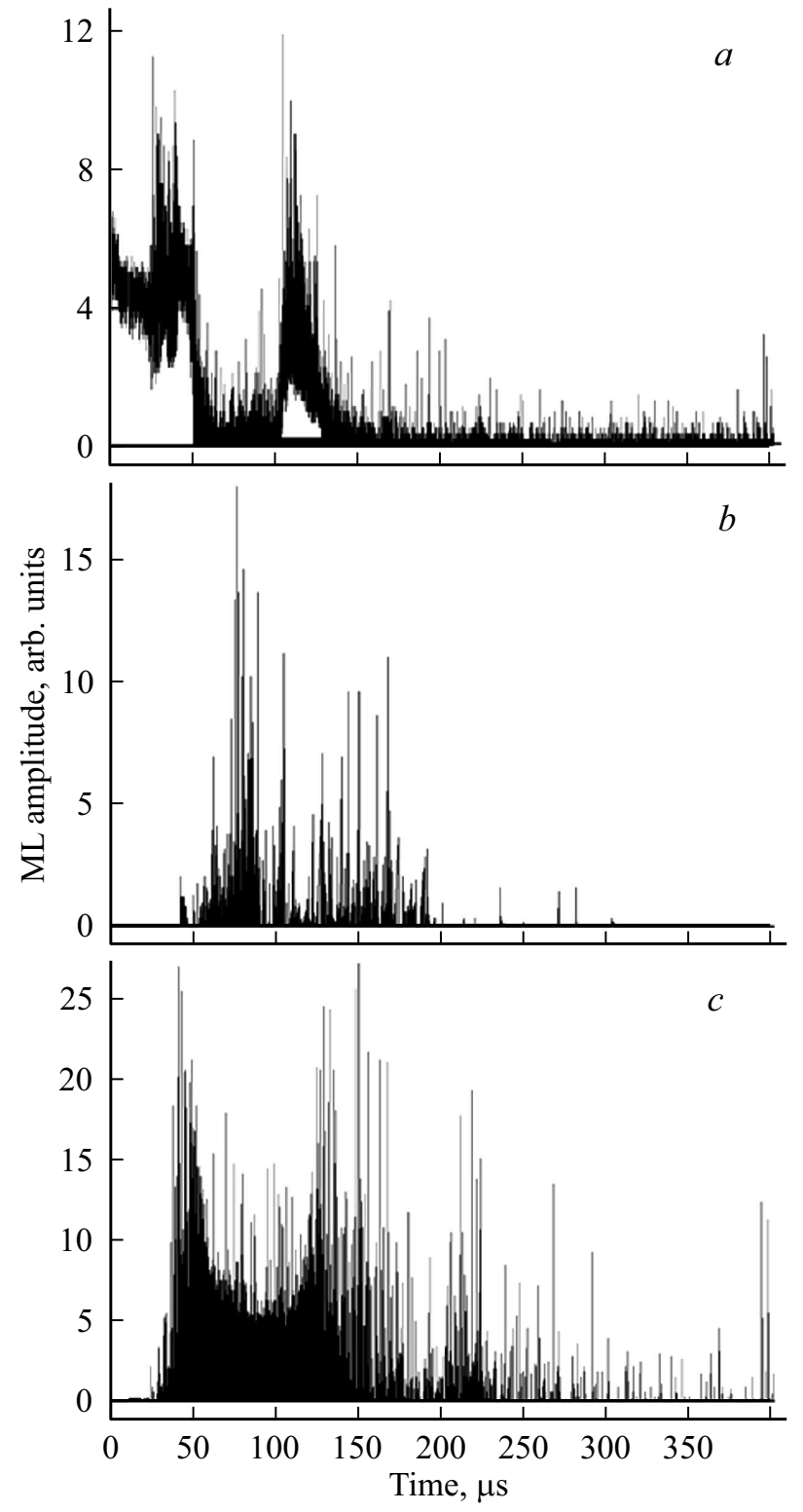

Рис. 2. Временнб́е серии импульсов МЛ при ударном воздействии на керамики $\mathrm{ZnSe}^{\mathrm{HP}}(a), \mathrm{ZnSe}^{\mathrm{PVD}}(b)$ и $\mathrm{ZnSe} \mathrm{PVD}^{\mathrm{HIP}}(c)$.

прессованием (образцы $\mathrm{ZnS}{ }^{\mathrm{CVD}+\mathrm{HIP}}, \mathrm{ZnSe}^{\mathrm{PVD}+\mathrm{HIP}}$ ) положение максимумов немного сместилось в сторону меньшего времени.

3.2. Распределения амплитуд. На рис. 3 и 4 для всех испытанных материалов приведены рассчитанные из временны́х разверток (рис. 1 и 2 соответственно) зависимости количества импульсов МЛ, в которых величина амплитуды $A$ превышает некоторый порог $A^{\prime}$ : $N\left(A>A^{\prime}\right)$ vs $A^{\prime}$. Все распределения амплитуд проявляют $\log$-линейные участки:

$$
\lg N\left(A>A^{\prime}\right) \propto-b \lg A^{\prime},
$$

масштаб изменения амплитуд МЛ в которых достигает 2-3 порядков (здесь $b-$ постоянная). Освобождаясь от логарифмов, получаем выражение (1) в степенной форме:

$$
N\left(A>A^{\prime}\right) \propto A^{\prime-b} .
$$

Некоторые закономерности, которые удалось выявить при сопоставлении распределений на рис. 1 и 2, обсудим ниже. В этом разделе заметим только, что наклон всех прямых (параметр $b$ ), описываемых зависимостью (1), различен во всех образцах. Величина $b$ характеризует соотношение условно „больших“ и „малых“ событий: чем меньше наклон, тем больше вклад в распределение более интенсивных импульсов МЛ. Например, можно видеть, что наклон распределений в пиках 1 временны́х
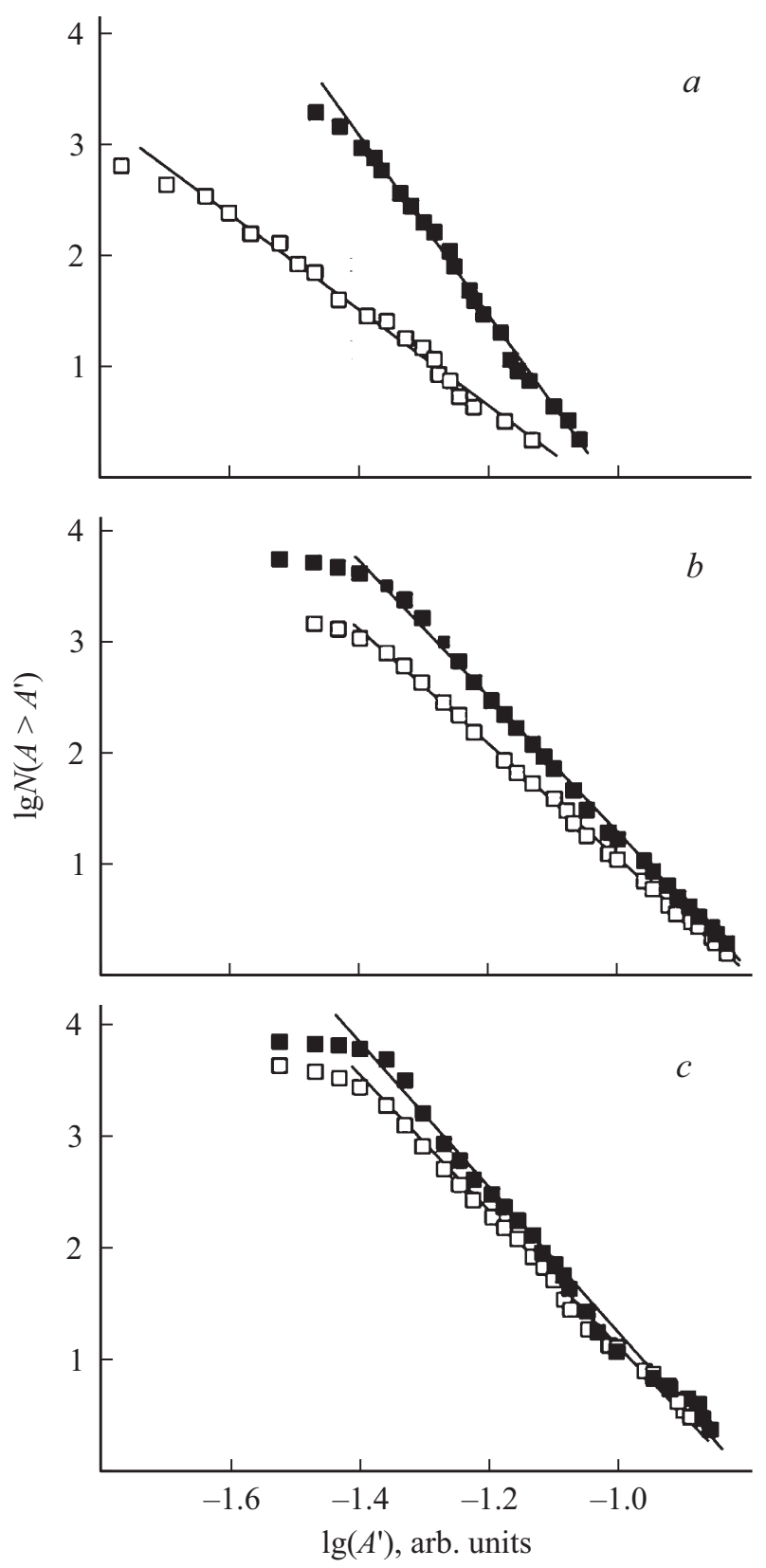

Рис. 3. Распределение амплитуд во временни́х сериях импульсов МЛ (рис. 1) керамик $\mathrm{ZnS}^{\mathrm{HP}}(a), \mathrm{ZnS}^{\mathrm{CVD}}(b)$ и $\mathrm{ZnS}^{\mathrm{CVD}+\mathrm{HIP}}(c)$. 

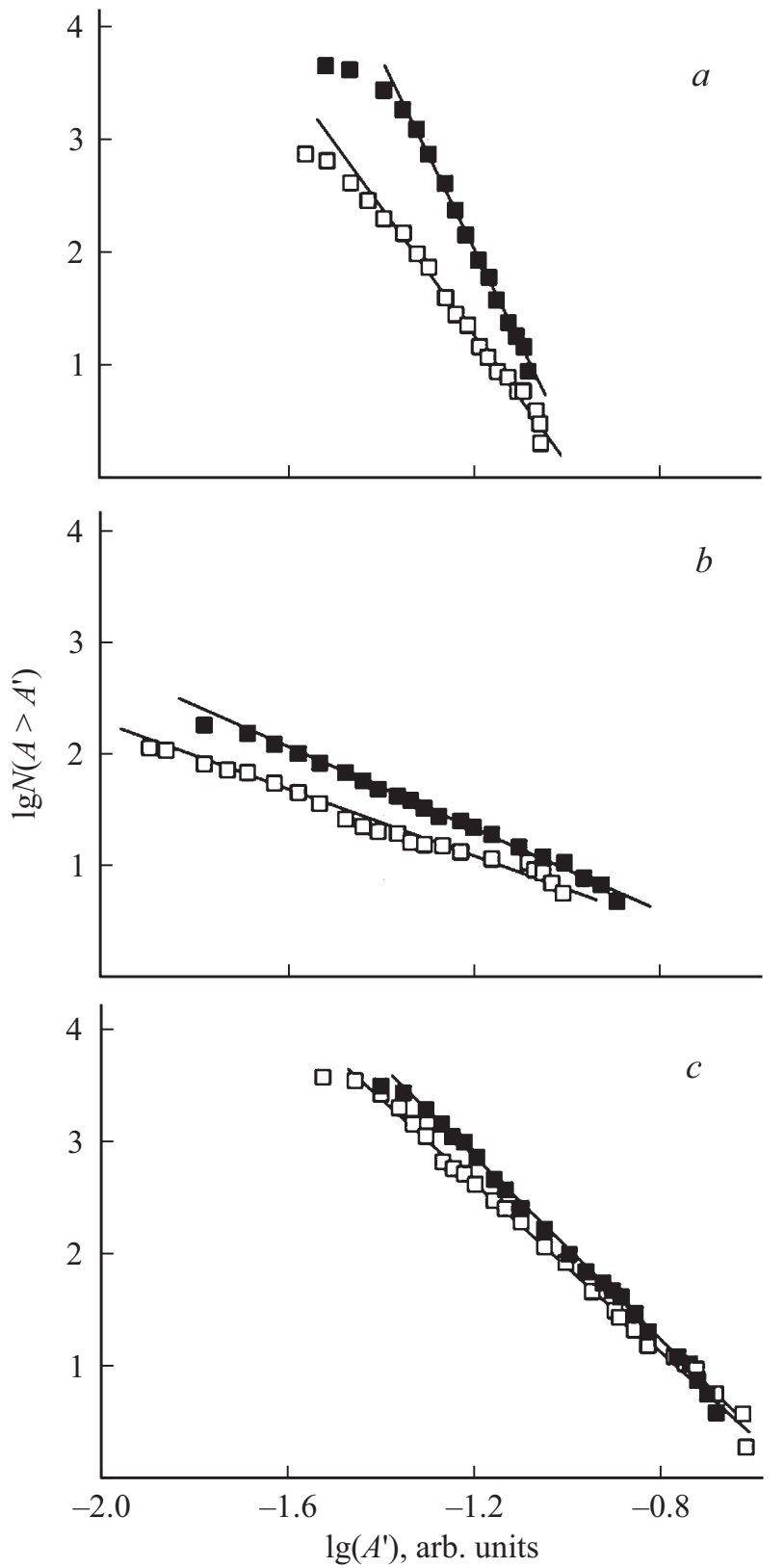

Рис. 4. Распределение амплитуд во временны́х сериях импульсов МЛ (рис. 1) керамик $\mathrm{ZnSe}^{\mathrm{HP}}(a), \mathrm{ZnSe}^{\mathrm{PVD}}(b)$ и $\mathrm{ZnSe}^{\mathrm{PVD}+\mathrm{HIP}}(c)$.

разверток всех образов был всегда выше, чем в пиках 2. Это означает, что выделение энергии при пластической деформации было ниже, чем при трещинообразовании. Кроме того, дополнительная термообработка образцов (HIP) привела к изменению величины $b$ в распределениях образцов, полученных методами CVD и PVD (табл. 2).

\section{4. Обсуждение}

Механическое поведение поликристаллических материалов зависит не только от свойств составляющих их
Таблица 2. Наклон $\log$-линейных участков (параметр $b$ ) на графиках распределения амплитуд (рис. 3, 4)

\begin{tabular}{l|c|c}
\hline Материал & Пик 1 & Пик 2 \\
\hline $\mathrm{ZnS}^{\mathrm{HP}}$ & $8.16 \pm 0.02$ & $4.16 \pm 0.11$ \\
$\mathrm{ZnS}{ }^{\mathrm{CVD}}$ & $4.47 \pm 0.04$ & $3.63 \pm 0.04$ \\
$\mathrm{ZnS}{ }^{\mathrm{CVD}+\mathrm{HIP}}$ & $5.79 \pm 0.13$ & $5.41 \pm 0.09$ \\
$\mathrm{ZnSe} \mathrm{HP}_{\mathrm{ZnSe}}^{\mathrm{PVD}}$ & $8.59 \pm 0.10$ & $5.37 \pm 0.09$ \\
$\mathrm{ZnSe}^{\mathrm{PVD}+\mathrm{HIP}}$ & $1.77 \pm 0.02$ & $1.35 \pm 0.06$ \\
& $4.21 \pm 0.04$ & $3.74 \pm 0.05$
\end{tabular}

кристаллов, но и от размера зерен и строения границ между зернами. В настоящем исследовании проявились все эти факторы, влияющие на ударное разрушение керамик $\mathrm{ZnS}$ и $\mathrm{ZnSe}$. Во-первых, в развертках МЛ всех образцов имелась „мертвая зона“ до появления пика 1 , которая могла быть связана с проскальзыванием зерен друг относительно друга без излучения света на первом этапе деформирования. Во-вторых, в обоих материалах наблюдалось существенное различие эффекта МЛ между образцами, полученными горячим прессованием $\mathrm{HP}$, и образцами, полученными физическим (PVD) и химическим (CVD) осаждением. Во временных сериях мелкозернистых образцов $\mathrm{ZnS}^{\mathrm{HP}}$ и $\mathrm{ZnSe}^{\mathrm{HP}}$ задержка начала свечения заметно меньше, чем в образцах $\mathrm{ZnS} \mathrm{CVD}^{\mathrm{C}}$ и $\mathrm{ZnSe} \mathrm{PVD}^{\mathrm{P}}$, построенных из более крупных кристаллитов (табл. 1). В образах $\mathrm{ZnS}^{\mathrm{CVD}+\mathrm{HIP}}$ и $\mathrm{ZnSe} \mathrm{PVD}^{\mathrm{HIP}}$ с редуцированными границами зерен задержка обоих пиков несколько короче, что можно объяснить сокращением цикла проскальзывания плотно связанных зерен. Период деформации без существенного разрушения структуры зерен-кристаллитов можно считать предварительной стадией формирования повреждения при внешнем воздействии на пластичный неоднородный материал.

После истощения эффекта проскальзывания появлялся первый пик МЛ, вызванный движением заряженных дислокаций $[5,16]$. Межкристаллитные границы препятствуют их перемещению. Как отмечалось выше, первая - „дислокационная“ - стадия свечения в мелкозернистых материалах $\mathrm{ZnS}^{\mathrm{HP}}$ и $\mathrm{ZnSe}^{\mathrm{HP}}$ имела наименьшую задержку, поскольку была ограничена свободным пробегом дислокаций внутри кристаллитов. $\mathrm{B}$ керамиках $\mathrm{ZnS} \mathrm{CVD}^{\mathrm{C}}$ и $\mathrm{ZnSe} \mathrm{PVD}^{\mathrm{P}}$, сложенных из более крупных кристаллитов, задержка МЛ, напротив, была максимальной.

По мере достижения предельной деформации источником люминесценции преимущественно становились разрывы межатомных связей, хотя некоторый вклад могла вносить локальная деформация среды в вершинах растущих трещин. Показанное в работе [8] совпадение положения пика 2 с моментом появления сигнала акустической эмиссии (слабо чувствительного к деформации) свидетельствует о незначительности фактора течения материала в трещинах.

Различие механизмов возбуждения МЛ пиков 1 и 2 подтверждается различием распределений амплитуд им- 
пульсов, рассчитанных по отдельности для обоих пиков. Все распределения следовали степенному закону (1a). Это указывает на кооперативный (коррелированный) характер элементарных процессов генерации света, происходящих как при пластической деформацией материала (пик 1), так и при зарождении микротрещин (пик 2). Эффект самоорганизации характерен для поведения ансамблей дислокаций [17], стимулированного пластической деформацией, а также для коррелированного накопления разорванных химических связей при возникновении и распространении трещин [18]. Как говорилось выше, указанным источникам МЛ соответствуют пики 1 и 2. Во всех распределениях наклон $\log$-линейных прямых для пиков 1 был выше, чем для пиков 2. Само по себе различие наклонов свидетельствует о различных механизмах возбуждения свечения на первом и втором этапах нагружения. Более высокое значение параметра $b$ в распределениях первых пиков соответствует сделанному на основании положения пиков 1 и 2 отнесению первичных вспышек люминесценции пластической деформации, а следующих за ними - разрыву межатомных связей. Действительно, можно было ожидать, что элементарные события излучения фотонов при движении дислокаций (высокое значение параметра $b$ ) производят меньший выход энергии, чем при образовании трещин (низкое значение параметра $b$ ).

Различие наклонов прямых $\lg N\left(A>A^{\prime}\right)$ vs $\lg A^{\prime}$, соответствующих пикам 1 и 2, было наибольшим в образцах $\mathrm{ZnS}^{\mathrm{HP}}$ и $\mathrm{ZnSe}^{\mathrm{HP}}$. Это показывает, что в мелкозернистых материалах, в которых межкристаллитные границы являются более существенным препятствием для вызванного ударной волной движения дислокаций [19], вклад в МЛ вследствие пластической деформации существенно уступает вкладу от зарождения и развития трещин. Напротив, в образцах, полученных методами CVD и PVD, параметры $b$ в пиках 1 и 2 были близки, т. е. соотношение количества импульсов в „больших“ и „малых“ событиях излучения света было приблизительно одинаковым при движении дислокаций и разрывах связей. Дополнительная обработка НІР привела к относительному уменьшению крупных вспышек свечения (ср. панели $b$ и $c$ на рис. 2, 3), причем этот эффект значительнее в более пластичном материале $\mathrm{ZnSe}$. Мы полагаем, что перераспределение амплитуд МЛ при переходах от $\mathrm{ZnS} \mathrm{CVD}^{\mathrm{C}}$ к $\mathrm{ZnS} \mathrm{CVD}^{\mathrm{HIP}}$ и от $\mathrm{ZnSe} \mathrm{PVD}^{\mathrm{P}} \mathrm{ZnSe} \mathrm{PVD}^{\mathrm{PV}+\mathrm{HI}}$ связано с тем, что отжиг не только уплотняет межкристаллитные границы, но и снижает плотность дислокаций и способность к зарождению трещин в более однородном материале.

\section{5. Заключение}

Представленные результаты показывают, что ударное разрушение пластичных керамик $\mathrm{ZnS}$ и $\mathrm{ZnSe}$ сопровождается люминесценцией, которая происходит в две стадии. Первый пик свечения возникает вследствие движения заряженных дислокаций при пластической деформации материала. При достижении предельной деформации происходят разрывы межатомных связей с перестройкой электронных структур, и появляется второй максимум свечения. Параметры временны́х серий импульсов МЛ зависят от размера кристаллических зерен и свойств границ между зернами, определяющих степень неоднородности материала. Статистический анализ распределений количества импульсов в зависимости от их амплитуды показал тенденцию к самоорганизации электронных процессов при различных механизмах их возбуждения на первом (пластическая деформация) и втором (образование трещин) этапах формирования механического повреждения образцов.

\section{Список литературы}

[1] Y. Kawaguchi. Solid State Commun. 117, 17 (2001).

[2] N. Brahme, M. Shukla, D.P. Bisen, U. Kurrey, A. Choubey, R.S. Kher, M. Singh. J. Lumin. 131, 965 (2011).

[3] N.C. Eddingsaas, K.S. Suslick. Nature 444, 163 (2006).

[4] G. Pallares, C.L. Rountree, L. Douillard, F. Charra, E. Bouchaud. Europhys. Lett. 99, (2012) 28003.

[5] С.И. Бредихин, С.З. Шмурак. ЖЭТФ 76, 1027 (1979).

[6] B.P. Chandra. In: Luminescence of Solids / Ed. D.R. Vij. Plenum Press, N. Y. (1998). P. 361-389.

[7] A. Chmel, I. Shcherbakov. J. Non-Cryst. Solids 369, 34 (2013).

[8] И.П. Щербаков, А.А. Дунаев, А.Г. Кадомцев, А.Е. Чмель. ФTT 58, 10 ( 2016).

[9] А.Г. Кадомцев, А.Е. Чмель, И.П. Щербаков. Физ. мезомех. 19, 74 (2016).

[10] G.H. Jilbert, J.E. Field. Wear 243, 1-2, 6 (2000).

[11] C.S. Chang, J.L. He, Z.P. Lin. Wear 255, 115 (2003).

[12] С.И. Бредихин, С.3. Шмурак. ЖЭТФ 73, 1460 (1977).

[13] Н.Ю. Макарова, А.Г. Спажакин, П.П. Корнилов, Ю.С. Клименко, Р.А. Скорняков. Тез. Всерос. конф. Актуальные проблемы авиации и космонавтики. Красноярск, 2005. C. 67.

[14] 3.Т. Рахманов, Т.Ю. Макарова, А.Г. Спажакин, К.В. Татмышевский. Пат. RU 2305847 (2007).

[15] А.Ф. Щуров, Е.М. Гаврищук, В.Б. Иконников, Э.В. Яшина, А.Н. Сысоев, Д.Н. Шеваренков. Неорган. материалы 40, 400 (2004).

[16] J. Pelleg. Mechanical Properties of Materials, Springer Science + Business Media, Dordreht, 2013, Ch. 3, p. 188.

[17] Г.А. Малыгин. УФН 169, 9, 979 (1999).

[18] A. Chmel, I. Shcherbakov. Fract. Struct. Integrity 30, 162 (2014).

[19] Г.А. Малыгин. ФТТ 57, 5, 955 (2015). 